\title{
Awake craniotomy to maximize glioma resection: methods and technical nuances over a 27-year period
}

\author{
Shawn L. Hervey-Jumper, MD, ${ }^{1}$ Jing Li, MD, ${ }^{1}$ Darryl Lau, MD,1 Annette M. Molinaro, PhD, ${ }^{1}$ \\ David W. Perry, PhD, ${ }^{2}$ Lingzhong Meng, MD, ${ }^{3}$ and Mitchel S. Berger, $\mathrm{MD}^{1}$
}

Departments of ${ }^{1}$ Neurological Surgery and ${ }^{3}$ Anesthesiology and Perioperative Care; and ${ }^{2}$ Surgical Neurophysiology, University of California, San Francisco, California

\begin{abstract}
OBJECT Awake craniotomy is currently a useful surgical approach to help identify and preserve functional areas during cortical and subcortical tumor resections. Methodologies have evolved over time to maximize patient safety and minimize morbidity using this technique. The goal of this study is to analyze a single surgeon's experience and the evolving methodology of awake language and sensorimotor mapping for glioma surgery.

METHODS The authors retrospectively studied patients undergoing awake brain tumor surgery between 1986 and 2014. Operations for the initial 248 patients (1986-1997) were completed at the University of Washington, and the subsequent surgeries in 611 patients (1997-2014) were completed at the University of California, San Francisco. Perioperative risk factors and complications were assessed using the latter 611 cases.
\end{abstract}

RESULTS The median patient age was 42 years (range 13-84 years). Sixty percent of patients had Karnofsky Performance Status (KPS) scores of $90-100$, and $40 \%$ had KPS scores less than 80 . Fifty-five percent of patients underwent surgery for high-grade gliomas, $42 \%$ for low-grade gliomas, $1 \%$ for metastatic lesions, and $2 \%$ for other lesions (cortical dysplasia, encephalitis, necrosis, abscess, and hemangioma). The majority of patients were in American Society of Anesthesiologists (ASA) Class 1 or 2 (mild systemic disease); however, patients with severe systemic disease were not excluded from awake brain tumor surgery and represented $15 \%$ of study participants. Laryngeal mask airway was used in 8 patients (1\%) and was most commonly used for large vascular tumors with more than $2 \mathrm{~cm}$ of mass effect. The most common sedation regimen was propofol plus remifentanil (54\%); however, $42 \%$ of patients required an adjustment to the initial sedation regimen before skin incision due to patient intolerance. Mannitol was used in $54 \%$ of cases. Twelve percent of patients were active smokers at the time of surgery, which did not impact completion of the intraoperative mapping procedure. Stimulation-induced seizures occurred in $3 \%$ of patients and were rapidly terminated with ice-cold Ringer's solution. Preoperative seizure history and tumor location were associated with an increased incidence of stimulation-induced seizures. Mapping was aborted in 3 cases $(0.5 \%)$ due to intraoperative seizures (2 cases) and patient emotional intolerance ( 1 case). The overall perioperative complication rate was $10 \%$.

CONCLUSIONS Based on the current best practice described here and developed from multiple regimens used over a 27-year period, it is concluded that awake brain tumor surgery can be safely performed with extremely low complication and failure rates regardless of ASA classification; body mass index; smoking status; psychiatric or emotional history; seizure frequency and duration; and tumor site, size, and pathology.

http://thejns.org/doi/abs/10.3171/2014.10.JNS141520

KEY WORDS awake craniotomy; glioma; glioblastoma; cortical stimulation mapping; cigarette smoking; diagnostic and operative techniques

$\mathrm{T}$ HE prevailing evidence suggests that a greater extent of resection positively affects overall survival, progression-free survival, and malignant transformation (low-grade gliomas) in adult patients with hemispheric gliomas. $., 14,21,26,30,48,50,51,55,56,58,61,64,65,72,77,79,82,89,95-97,100,102,103,109-$
${ }^{111,113}$ Mapping of language and sensorimotor function is the gold standard to achieve maximal safe resection, particularly for tumors in presumed functional areas. Throughout the history of neurosurgery, awake craniotomies have been used for various indications with the overarching

ABBREVIATIONS ASA = American Society of Anesthesiologists; $B M I=$ body mass index; ECoG = electrocorticography; KPS = Karnofsky Performance Status; $L M A=$ laryngeal mask airway; $\mathrm{MSI}=$ magnetic source imaging; UCSF = University of California, San Francisco.

SUBMITTED June 30, 2014. ACCEPTED October 24, 2014

INCLUDE WHEN CITING Published online April 24, 2015; DOI: 10.3171/2014.10.JNS141520.

DISCLOSURE The authors report no conflict of interest concerning the materials or methods used in this study or the findings specified in this paper. 
goal of enhancing safety. Since the original description of awake craniotomy by Horsley more than 120 years ago, popularization by Penfield, and subsequent introduction into the modern era by Ojemann and others, different techniques and methodologies have been described in the literature for the testing and identification of functional sites $^{34,47,69,74,87}$ A meta-analysis examining the usefulness of intraoperative stimulation mapping revealed a 58\% reduced morbidity and improved extent of resection with the use of stimulation mapping (compared with no stimulation mapping).$^{29}$ Yet, despite its utility, awake craniotomy for mapping is used in less than $22 \%$ of glioma surgeries. ${ }^{20}$ This is possibly due to the complexity of the procedure, variable patient selection criteria, prevalence of stimulation-induced seizures, and failure rates as high as $6.4 \% .66,67$ Over the past 20 years, studies involving more than 3000 patients have suggested failure rates of $2.3 \%-6.4 \%$, with reasons including poor patient selection, inadequate anesthetic regimen, and intraoperative stimulation-induced

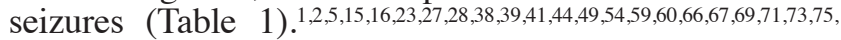
76,83-85,87,90,92,94,99,104,107,108 Previously published studies have demonstrated the value of cortical and subcortical mapping for glioma resections, along with the importance of extent of resection for both high- and low-grade gliomas. ${ }^{11,17-19,29,35,36,43,52,53,80,81,86-89,98,100,101,106}$ Due to the reported variability of success rates for completing an awake craniotomy, along with the many published techniques and methods of performing the procedure, we decided to review the extensive experience of a single surgeon with the goal of identifying the optimal techniques and regimen to maximize perioperative safety and minimize the risk of failure for patients undergoing awake craniotomies during the removal of a glioma.

\section{Methods}

We retrospectively studied 859 patients undergoing awake brain tumor surgery (asleep-awake-asleep sedation technique) performed by 1 surgeon (M.S.B.) for tumors in functional regions of the brain for the period 1986-2014. The series began in 1986 and was carried out at the University of Washington School of Medicine until early 1997. During that time, 248 patients underwent an awake language and sensorimotor mapping craniotomy. Because these patient records were not available in full detail, we could not comment on perioperative complications or patient risk factors. We were, however, able to identify the number of patients who successfully completed awake language and sensorimotor mapping craniotomy after review of intraoperative brain maps and pre- and postoperative imaging. The remaining 611 patients were treated between 1997 and April 2014 at the University of California, San Francisco (UCSF) and constitute the data set for this study.

\section{Patient Selection}

Patients were included in the study if they had a supratentorial lesion located within or adjacent to regions presumed to have language or sensorimotor function on preoperative MRI. Initial concerns about awake craniotomy necessitated the adoption of relative contraindications to guide proper patient selection. As the technique evolved, solutions were adopted to prevent these concerns from allowing a safe awake craniotomy, even in high-risk patients (Table 2). For example, patients with significant mass effect (more than $2 \mathrm{~cm}$ of midline shift), despite preoperative diuretics and corticosteroids, were offered a staged procedure, although this approach was seldom needed. Stage 1 involved internal debulking for removal of mass effect in an asleep patient using functional and anatomical imaging (magnetic source imaging [MSI]) followed by reoperation several weeks later with awake mapping for the identification and preservation of functional sites. Obese patients (body mass index $[\mathrm{BMI}]>30$ ) and those with obstructive

TABLE 1. Prior published series of awake craniotomies

\begin{tabular}{lcccl}
\hline \multicolumn{1}{c}{ Authors \& Year } & $\begin{array}{c}\text { No. of } \\
\text { Patients }\end{array}$ & $\begin{array}{c}\text { Intraop } \\
\text { Seizures }\end{array}$ & Failure & \multicolumn{1}{c}{ Complications } \\
\hline Nossek et al., 201367 & 477 & $12.6 \%$ & $2.3 \%$ & NS \\
\hline Trinh et al., 2013 & 214 & NS & NS & New neurological deficit (38\%); 3-mo neurological deficit (3\%) \\
\hline Nossek et al., 201366 & 424 & NS & $6.4 \%$ & $4.7 \%$ \\
\hline Grossman et al., 2013 & 90 & $2.2 \%$ & NS & New motor deficit (14\%); new language deficit (8.7\%); hemorrhage \\
& & & & $(3.3 \%)$ \\
\hline Peruzzi et al., 2011 & 22 & NS & NS & $18 \%$ \\
\hline Sacko et al., 2011 & 214 & $5.7 \%$ & NS & $33.6 \%$ \\
\hline Conte et al., 2010 & 238 & $16 \%$ & NS & Emergency intubation (5\%); apnea (4\%); agitation (6\%) \\
\hline Pereira et al., 2009 & 79 & $21.5 \%$ & $2.5 \%$ & Stroke (6.3\%); infection (2.5\%); DVT/PE (5.1\%) \\
\hline Serletis \& Bernstein, 2007 & 511 & $4.9 \%$ & NS & New neurological deficit (15.3\%) \\
\hline Gupta et al., 2007 & 26 & NS & NS & New neurological deficit (23\%) \\
\hline Skucas \& Artru, 2006 & 332 & $3 \%$ & NS & $5 \%$ \\
\hline Sarang \& Dinsmore, 2003 & 99 & $5 \%$ & NS & NS \\
\hline Archer et al., 1988 & 354 & $16 \%$ & NS & NS \\
\hline Gignac et al., 1993 & 30 & $16.7 \%$ & NS & NS \\
\hline Herrick et al., 199745 & 37 & $18.9 \%$ & NS & NS \\
\hline
\end{tabular}

DVT = deep venous thrombosis; NS = not stated in study; $\mathrm{PE}=$ pulmonary embolism. 
TABLE 2. Relative contraindications and solutions for awake craniotomy patients

\begin{tabular}{|c|c|}
\hline Prior Concerns & Current Solutions \\
\hline $\begin{array}{l}\text { Significant mass effect ( }>2-\mathrm{cm} \text { midline shift) despite } \\
\text { preoperative diuretics \& steroid }\end{array}$ & $\begin{array}{l}\text { Staged internal debulking (asleep) using functional imaging (MEG/MSI) } \\
\text { followed by reoperation w/ awake mapping or LMA }\end{array}$ \\
\hline Obese patient (BMI >30)/obstructive apnea & $\begin{array}{l}\text { LMA before \& after mapping (limits subcortical mapping during resec- } \\
\text { tion if LMA is used) }\end{array}$ \\
\hline Psychiatric history/emotional instability & Treated mood disorders no longer a contraindication \\
\hline \multicolumn{2}{|l|}{ Age (yrs) } \\
\hline$>10$ & Awake \\
\hline$<10$ & 2-stage procedure w/ implanted grid \\
\hline Intraop seizures & Iced Ringers solution, propofol IV 6 inches from vein \\
\hline Smoker & Cough suppressants w/ or w/o light sedation \\
\hline Intraop nausea & $\begin{array}{l}\text { Preop medication w/ antiemetic drugs (ondansetron hydrochloride, } \\
\text { scopolamine) \& high-dose dexamethasone (10 mg) }\end{array}$ \\
\hline Reop (dural scar) & Focused craniotomy w/ negative mapping is acceptable \\
\hline Severely impaired preoperative function* & $\begin{array}{l}\text { Attempt to improve function w/ up to } 5 \text { days of preoperative high-dose } \\
\text { steroids w/ or w/o diuretics }\end{array}$ \\
\hline $\begin{array}{l}\text { Tumor location presumed to be w/in functional cortical } \\
\text { or subcortical pathways on preop imaging }\end{array}$ & $\begin{array}{l}\text { The decision to offer surgery is not made based on preop anatomical or } \\
\text { functional imaging (attempt is always made to map, identify, \& pre- } \\
\text { serve functional sites). }\end{array}$ \\
\hline
\end{tabular}

$\mathrm{BMI}=$ body mass index; IV = intravenous; $\mathrm{MEG}$ = magnetoencephalography; $\mathrm{MSI}$ = magnetic source imaging.

${ }^{*}$ Motor function $<2 / 5$ or baseline naming/reading errors.

sleep apnea may be treated with a laryngeal mask airway (LMA) to control hypercapnia. Patients with a psychiatric history and emotional instability were treated preoperatively with antidepressant mood-stabilizing medications. Children younger than 10 years of age were treated with a 2-stage procedure using subdural grids, while children older than 10 years underwent an awake craniotomy. Patients with frequent preoperative seizures who experienced seizures during the intraoperative mapping had iced Ringer's solution applied to the cortex during stimulation. Intravenous propofol was maintained in a large-bore intravenous line within 6 inches from the vein for rapid administration. Smokers and patients with a chronic cough were treated preoperatively with chronic cough suppressants and light sedation. Intraoperative nausea was treated with preoperative antiemetic medications (ondansetron hydrochloride, and scopolamine). Patients with severely impaired preoperative function (greater than 25\% naming errors and a Medical Research Council scale score less than 2 of 5) were treated with 3-5 days of high-dose corticosteroids (intravenous dexamethasone, $4-8 \mathrm{mg}$ every 6 hours) and/or diuretics (mannitol 20\%, 30 g every 6 hours for 48-72 hours) followed by reassessment of preoperative function. If language function did not improve, a staged procedure as described above was offered. Tumor location presumed to be within functional cortical or subcortical sites on preoperative anatomical imaging was never a contraindication to attempting intraoperative mapping to identify function as opposed to assuming that the patient could not be mapped. The decision to offer surgery was not made based on preoperative functional imaging due to the less-than-ideal specificity and sensitivity of localized function. ${ }^{12,40,46,62,63,93,105,112}$ The patient was always taken to the operating room, and the tumor and surrounding brain were mapped to determine how much of a resection could be performed..$^{5,6,29,59,70,84,85,87}$ Absolute contraindications to surgery included uncontrolled coughing, severe dysphasia, greater than $25 \%$ naming errors despite a trial of preoperative dexamethasone and mannitol, and hemiplegia with less than antigravity motor function.

\section{Preoperative Evaluation}

Preoperative imaging included MRI with and without gadolinium enhancement, diffusion tensor imaging for white matter pathways including the corticospinal tract, superior longitudinal fasciculus, arcuate fasciculus, uncinate fasciculus, interior orbitofrontal fasciculus, optic pathways, and connectivity maps using MSI with magnetoencephalography. ${ }^{8,68,105}$ Preoperative clinical evaluation included baseline language assessment performed by our surgical neurophysiology team (D.W.P.). All patients were counseled prior to surgery, during which time the procedure was described in detail. Baseline language and sensorimotor testing was performed 24-48 hours prior to surgery and included naming (64-object panel), reading, spelling, calculations, visuospatial, and comprehension testing depending on tumor location (Fig. 1). ${ }^{37}$ The full 64-object naming battery was modified preoperatively, removing objects, words, and tasks that the patient had difficulty performing. Intraoperative testing used only pictures and words that an individual patient was able to reliably answer correctly based on preoperative evaluation. Preoperative neuropsychological evaluation was performed for selected individuals especially if requested by the patient (performed in $2 \%$ of cases).

\section{Current Technique}

Patient Positioning and Anesthesia Regimen

Specialized neuroanesthesia is critical for a success- 


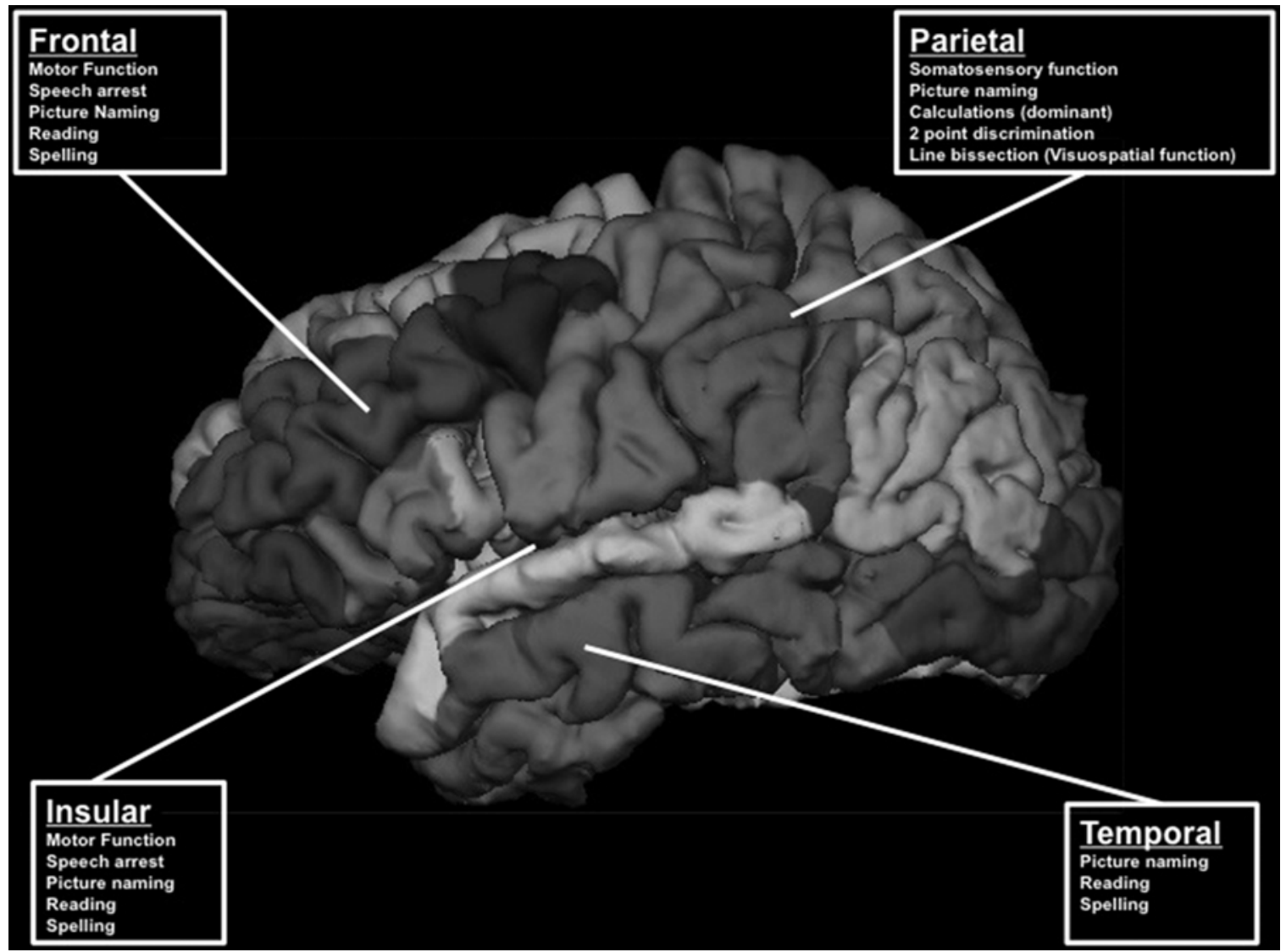

FIG. 1. Site-specific testing for the identification of functional sites.

ful awake craniotomy and requires clear communication between the surgeon and anesthesiologist to ensure ideal intraoperative mapping conditions (Fig. 2). Patient monitors are applied (including blood pressure cuff and arterial line placement), followed by premedication with 1-2 $\mathrm{mg}$ of midazolam and $50 \mu \mathrm{g}$ of fentanyl prior to positioning. The operating room is preheated, and warm blankets and Bair Huggers (3M Corp.) are used to keep the patient warm to avoid shivering and allow for an optimal patient temperature between $36.0^{\circ}$ and $37.0^{\circ} \mathrm{C}$ for mapping. Demerol is not used to treat shivering during any awake craniotomies because of its prolonged sedating effects. All patients are given supplemental oxygen via nasal cannula. A nasal trumpet is placed if the patient shows evidence of airway obstruction or snoring with sedation. A low-dose propofol infusion is started during the Foley catheter insertion and Mayfield headholder pin placement. After the Foley catheter is inserted, an initial dose of mannitol may be given to lessen cerebral edema (particularly for patients with $>2 \mathrm{~cm}$ mass effect, high-grade tumors, or high BMI). Monitored sedation using propofol or dexmedetomidine plus remifentanil is used; however, if the patient becomes disinhibited, this initial drug regimen may be adjusted. On occasion, the patient remains fully awake during surgery to improve participation and maximize safety. The patient is positioned semilateral with his or her head positioned optimally for the surgical procedure while allowing access for the potential LMA placement, if needed. These early steps require a great deal of flexibility on the part of the surgeon, as the initial sedation regimen can change depending on patient tolerance. Using neuronavigation, a focused craniotomy is planned and the scalp incision is outlined. A complete scalp block or regional field block just behind the incision (a 1:1 mixture of 1\% lidocaine with 1:100,000 epinephrine, $0.5 \%$ bupivacaine, plus $4.5 \mathrm{ml}$ of $8.4 \%$ sodium bicarbonate) is injected. A dedicated intravenous line is filled with a $1-\mathrm{mg} / \mathrm{kg}$ bolus of propofol 6 inches from the vein if needed for suppression of intraoperative seizures. Sedation is achieved with propofol (up to $100 \mu \mathrm{g} / \mathrm{kg} / \mathrm{min})$ and remifentanil (0.07-2.0 $\mu \mathrm{g} / \mathrm{kg} / \mathrm{hr})$. Patients who show apnea or intolerance to propofol (particularly young males) may be given dexmedetomidine (up to $1 \mu \mathrm{g} / \mathrm{kg} / \mathrm{min}$ ) as an alternative to propofol. ${ }^{4,7,9,10,13,22-25,71,78,90}$ In patients who tend to be anxious, a very-low-dose remifentanil infusion may be used during and after cortical mapping.

\section{Craniotomy Opening}

The overall goal is to perform a focused exposure encompassing the lesion plus a 2- to 4-cm margin, depending on the need to map adjacent functional tissue. For reoperations and patients with an extensive dural scar, the craniotomy is focused to open the dura only overlying the lesion so as to avoid cortical injury to the surrounding brain. The temporalis muscle is separated and retracted inferiorly for most anterior frontal and insular lesions, or 


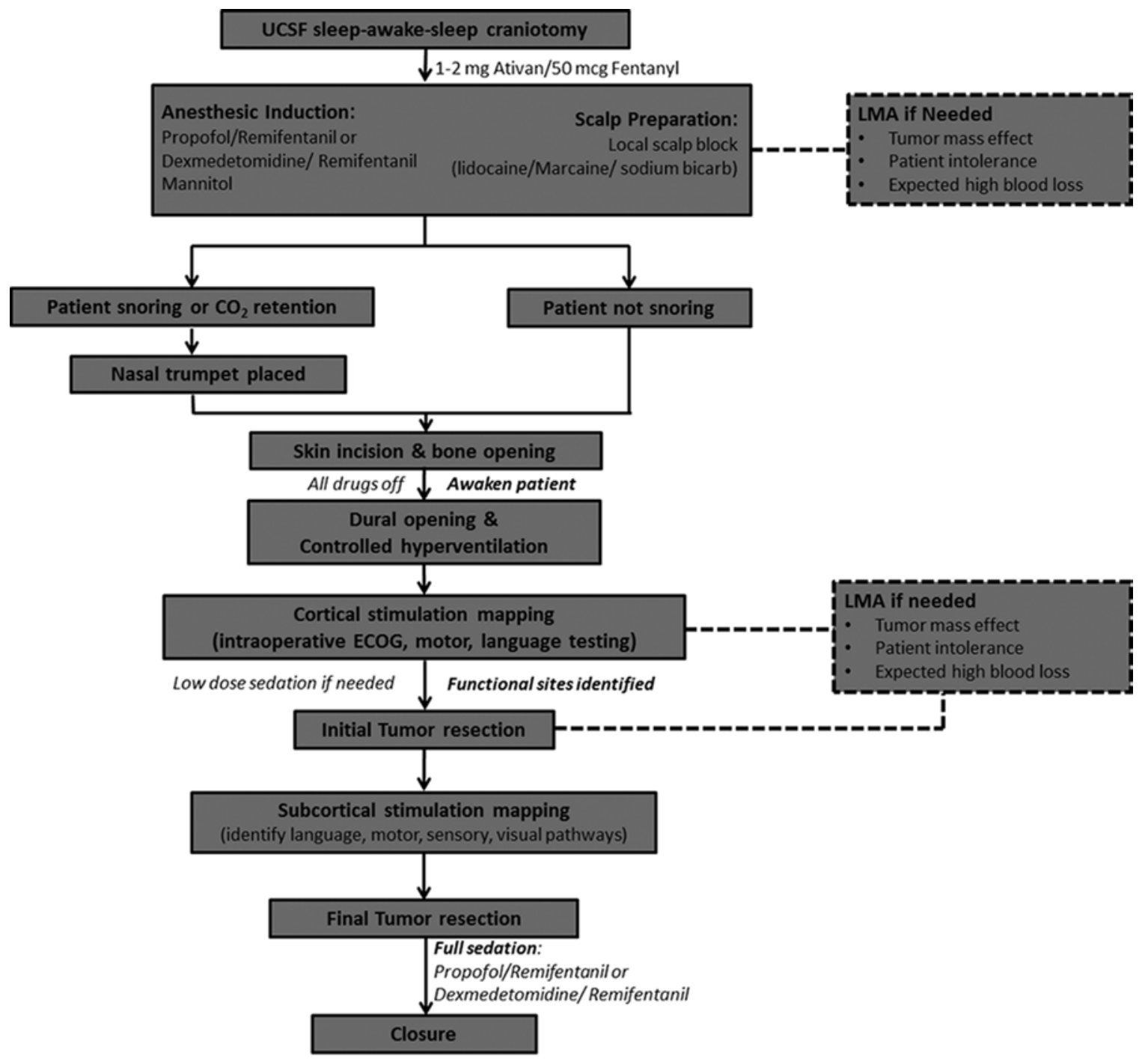

FIG. 2. UCSF awake craniotomy flowchart.

anteriorly for posterior frontal and temporal lesions. Upon removal of the bone flap, all medications are discontinued unless the patient is very anxious, and the patient is asked to take multiple deep breaths for controlled hyperventilation before opening the dura. The dura is opened in whichever manner best suits optimal exposure of the lesion. Care is always taken to not coagulate the dura, using a heavy clamp to cut down on dural bleeding at the edges followed by tack-up sutures. Upon opening the dura, the brain is assessed for swelling, at which time the patient may be instructed to perform additional controlled hyperventilation. Alternatively, the patient may be given additional mannitol, the head of the bed raised, and the arachnoid space opened for release of CSF as additional maneuvers to decrease brain swelling. Mannitol is avoided in patients with deep lesions in the ventricle, in any situation in which the ventricle will be opened, or in lesions close to a cistern or deep fissure, since copious amounts of CSF will be lost early in the procedure, promoting too much brain relaxation. A dural block is performed using a
30 -gauge needle with $1 \%$ lidocaine to infiltrate the region around the middle meningeal artery.

\section{Cortical and Subcortical Stimulation Mapping}

Before stimulation mapping begins, we ensure that iced Ringer's solution is readily available on the surgical field for rapid termination of intraoperative stimulationinduced seizures, as previously described.${ }^{91}$ Stimulation is delivered using a bipolar electrode, beginning with $2 \mathrm{~mA}$ increased to a maximum of $6 \mathrm{~mA}$ until somatosensory or motor function is established, or after-discharge potentials are detected on intraoperative electrocorticography (ECoG) when mapping language..$^{84,85,87} \mathrm{~A}$ constant current generator delivers 1.25 -msec biphasic square waves in 4 -second trains at $60 \mathrm{~Hz}$. Stimulation is delivered across $1-\mathrm{mm}$ bipolar electrodes separated by $5 \mathrm{~mm}$.

Stimulation begins with identification of primary sensory and motor areas if the posterior frontal and anterior parietal lobes are exposed. When cortical sensory and motor areas are not exposed, a 4-contact strip electrode can 
be advanced under the edges of the dura opening to elicit a motor or sensory response. As the technique has evolved, there is growing reliance on negative language and sensorimotor mapping with focused craniotomies, which do not contain positive stimulation sites. ${ }^{87}$ Intraoperative ECoG is performed using a 16-array cortical electrode and holder assembly designed to record electroencephalography readings from the exposed cortex (Grass Model CE1, Natus Medical Inc.). An epileptologist deciphers ECoG readings for detection of after-discharges or epileptiform activity following cortical stimulation. During language testing, a current is used that is $1 \mathrm{~mA}$ lower than the current that evoked after-discharge potentials to an upper limit of 6 $\mathrm{mA}$. The typical current used is $3-4 \mathrm{~mA}$.

When in the perisylvian region of the frontal and temporal operculum, the patient is asked to either count from 1 to 30 or speak the letters of the alphabet to identify sites of speech arrest. Approximately 10-20 numerically marked simulation sites separated by $1 \mathrm{~cm}$ are placed on the surgical field. Language testing seeks to identify sites responsible for speech arrest, anomia, and alexia on stimulation. Speech arrest is defined as discontinuation in number counting without a simultaneous motor response (e.g., mouth or pharynx motor response) ${ }^{87}$ Dysarthria is distinguished from speech arrest by an absence of involuntary muscle contractions affecting speech. ${ }^{87}$ Stimulation is applied for 3-4 seconds at sequential sites with tasks separated by $4-10$ seconds. During testing, a neurophysiologist (D.W.P.) displays each slide to the patient and records the positive or negative result and the type of language disturbance of each stimulation point as the site number stimulated is called out by the neurosurgeon. According to the established protocol initially established by Ojemann et al., all language stimulation testing is repeated at least 3 times, and a positive site is defined as the inability to count, name objects, or read words during stimulation in more than $66 \%$ of attempts. ${ }^{28,69,84,87} \mathrm{~A} 1-\mathrm{cm}$ margin of tissue is usually preserved in all cases around positive language sites to protect language function. ${ }^{55,84}$ However, the $1-\mathrm{cm}$ margin rule can be violated to enhance extent of resection while the patient is being tested to avoid postoperative language deficits. The patient is tested both for the identification of cortical as well as subcortical sites using the same stimulation parameters. ${ }^{53}$ In our previously published experience focusing specifically on cortical language mapping, 58\% of patients had at least 1 positive site. ${ }^{87}$ Similarly, our previously published motor mapping experience found that $45 \%$ of patients had positive cortical or subcortical mapping with a $2.1 \%$ morbidity associated with negative subcortical mapping and $7.4 \%$ morbidity associated with positive subcortical mapping. ${ }^{53}$ The morbidity associated with positive subcortical language function has yet to be examined in the literature.

\section{Evolution of Technique}

The awake mapping technique has evolved over 27 years. The reasons for this change can be summarized into 4 basic categories: 1) improved neuroanesthesia, 2) improved intraoperative seizure management, 3) improved surgical technique and broadened intraoperative testing, and 4) a better understanding of functional language pathways and brain remodeling. Initially, anesthesia involved no sedation with local scalp and regional blocks using lidocaine and bupivacaine hydrochloride (Fig. 3) ${ }^{69}$ Neuroleptic anesthesia using droperidol was the initial sedation regimen until monitored anesthesia care using propofol was introduced in the early 1990s. Propofol was immediately recognized for its sedating characteristics in addition to its ability to suppress seizure activity. An early publication by Herrick et al. compared these 2 agents in a prospective fashion, noting significantly fewer seizures in patients undergoing awake craniotomy using propofol. ${ }^{44}$ In the early $2000 \mathrm{~s}$, dexmedetomidine was identified as another potential alternative for patient sedation with the addition of the short-acting opioid remifentanil. ${ }^{4}$ Regardless of the anesthetic regimen, over-sedation during the sleep portion of surgery can lead to carbon dioxide retention, which can be particularly problematic in overweight patients, those with significant tumor mass effect (greater than $2 \mathrm{~cm}$ of midline shift), or in cases of expected highvolume blood loss. When the LMA became commercially available in the early $1990 \mathrm{~s}$, it offered a potential solution to this problem and became a useful tool for the sleep portion of surgery, allowing airway management and potential hyperventilation. Additionally, a nasal trumpet may be placed for those patients who snore excessively or retain carbon dioxide.

An understanding of the value of negative mapping altered surgical technique by allowing smaller, tailored craniotomies based on the extent and location of each individual tumor (Fig. 4) ${ }^{87}$ The initial testing paradigm included naming and reading; now using preoperative MRI, each patient receives tailored, site-specific testing.

Intraoperative seizure control has always been a major concern during awake brain tumor surgery. Early on it was identified as a major contributor to aborted procedures and associated with increased perioperative morbidity. The introduction of intraoperative ECoG allowed not only the identification of after-discharge potentials, but also marked the threshold current for intraoperative testing, thereby initiating testing at lower currents $(1 \mathrm{~mA}$ below after-discharge potentials). Intraoperative stimulationinduced seizures were initially controlled with intravenous lorazepam. Treatment with these short-acting benzodiazepines often necessitated cessation of intraoperative testing. Therefore, the discovery that iced Ringer's solution applied locally to the cortical surface offered a mechanism of seizure control without the sedating effects of short-acting benzodiazepine drugs was a major contribution leading to improved success rates. ${ }^{91}$

A heightened understanding of the importance of brain remodeling (plasticity) and an appreciation of functional white matter pathways in glioma patients led to further changes in technique. Before functional imaging modalities were readily available in the operating room, early studies stated the significance of stimulation within $2 \mathrm{~cm}$ of sites for stimulation-induced anomia. ${ }^{69} \mathrm{In}$ an attempt to perform even more complete resections, further analysis identified $1 \mathrm{~cm}$ as the critical distance necessary to maintain normal language function. ${ }^{42}$ We now know that glioma resections can take place within $1 \mathrm{~cm}$ of functional sites with excellent short- and long-term outcomes. This is likely due to a growing acceptance of the activation of latent functional pathways in addition to functional path- 


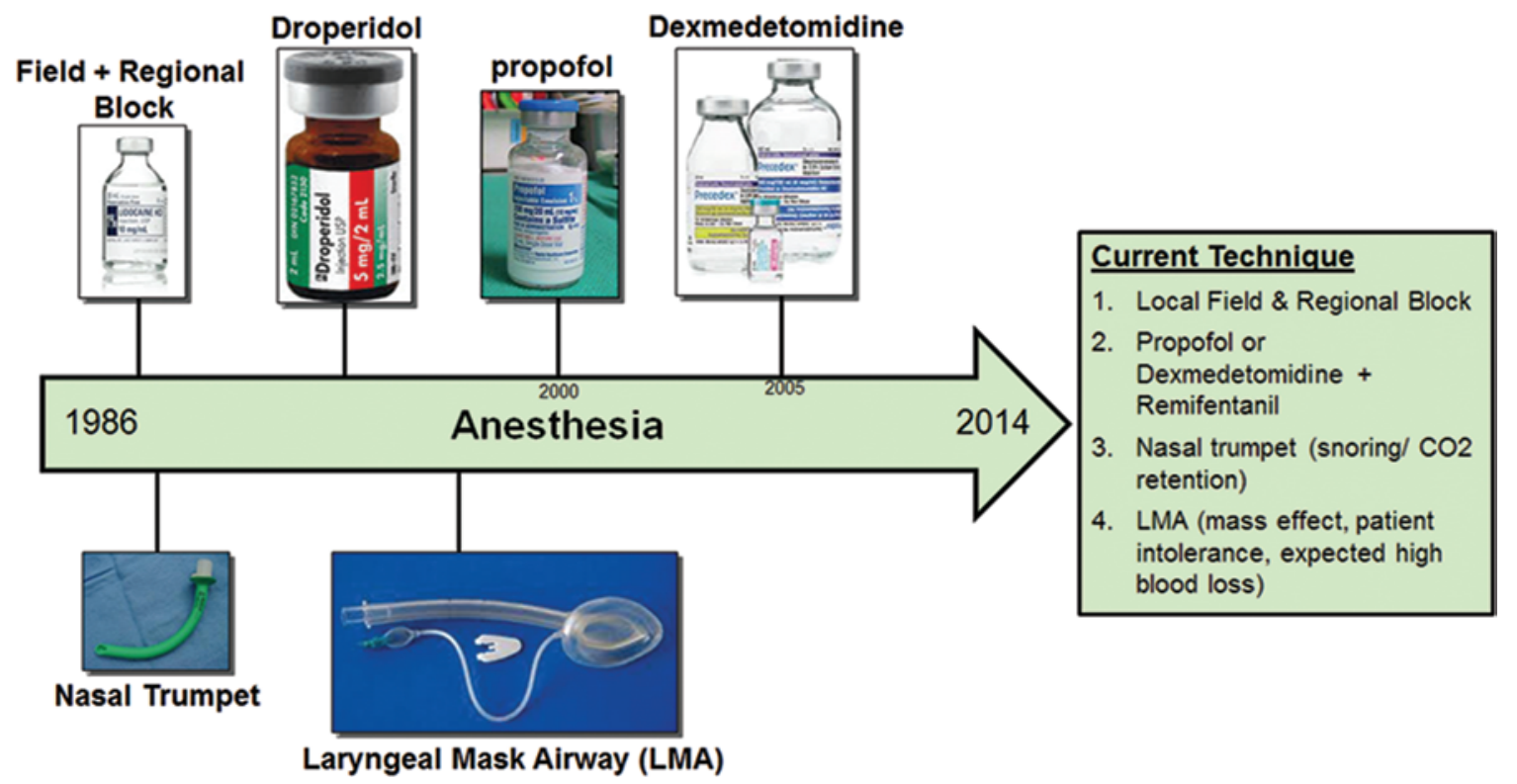

FIG. 3. Evolution of the anesthetic regimen over time. Figure is available in color online only.

way remodeling in glioma patients. ${ }^{32}$ Based on recently published work recognizing cortical plasticity in glioma patients, partial resections are now reasonable when tumor occupies functional regions. At the time of recurrence, the tumor and surrounding cortical surface are remapped to attempt further resection if plasticity has allowed function to move away from the tumor. ${ }^{31-33}$ Although the incidence and mechanism of this are poorly understood, they are both thought to be contributing factors to the short- and long-term recovery of language function.

Once functional sites are identified, a distance of $2 \mathrm{~cm}$ to the resection margin was originally advocated, ${ }^{69}$ and then a shift was made to $1 \mathrm{~cm} ;{ }^{42}$ however, resections are now advanced to within $1 \mathrm{~cm}$ of functional sites or until intraoperative language deficits begin to occur. Based on recently published work recognizing cortical plasticity in glioma patients, partial resections are now allowed when tumor occupies functional regions. At the time of recurrence, the tumor and surrounding cortical surface are remapped to attempt further resection if plasticity has allowed function to move away from the tumor. ${ }^{31-33}$

\section{Statistical Analysis}

Descriptive statistics are given as median (range) unless otherwise specified for continuous variables and frequency of distribution for categorical variables. The Pearson chi-square test was used for categorical analyses, and ttests were performed for mean comparisons of continuous variables. The Fisher exact test was used if more than $80 \%$ of values were less than 5 . All statistics were analyzed using JMP statistical software, version 10.0.2 (SAS Institute). A biostatistician contributed in the statistical analysis for this study (A.M.M.). The UCSF institutional review board approved the study.

\section{Results}

A total of 611 consecutive patients were treated between
June 1997 and April 2014 at UCSF with records complete for identification of perioperative complications, mapping details, and successful completion of the surgical procedure (Table 3 ). The median patient age was 42 years (range 13-84 years). Sixty percent of patients had KPS scores of 90-100, and 40\% had KPS scores lower than 80. Lesion location was most commonly temporal (36\%), followed by frontal (27\%), insular (21\%), and parietal (15\%). Ninetyfour percent of patients had left-sided lesions. Language mapping was performed in $98 \%$ of patients and motor mapping in 56\%. Three hundred thirty-five (55\%) patients had high-grade tumors (WHO Grades III and IV), 259 (42\%) had low-grade tumors (WHO Grades I and II), 3 (1\%) had metastatic lesions, and 14 (2\%) had other lesions (cortical dysplasia, encephalitis, necrosis, abscess, or hemangioma). The median BMI was 25 (range 16.6-56). Patients with low BMI $(<24.9)$ represented $42 \%$ of patients and those with high BMI (> 25) represented $58 \%$ of patients. The majority of patients (84\%) had mild systemic disease (American Society of Anesthesiologists [ASA] Class 1 or 2); however, $15 \%$ of patients had severe systemic disease. Preoperative airway analysis revealed complete visualization of the soft palate and uvula in $87 \%$ of patients (Mallampati Class 1 or 2); however, those with incomplete visualization (Mallampati Classes 3 and 4) represented $13 \%$ of patients. Twelve percent of patients had a preoperative history of depression, $12 \%$ of patients were active smokers, and $5 \%$ had a chronic cough at the time of awake craniotomy. Mannitol was used in $54 \%$ of patients.

\section{Sedation Technique}

The asleep-awake-asleep monitored anesthesia care technique employed the following drug regimens for sedation: dexmedetomidine plus remifentanil (4\%), propofol plus remifentanil (54\%), or an adjusted technique (42\%) in which the initial anesthetic regimen was modified via the addition or subtraction of sedating drugs due to patient 


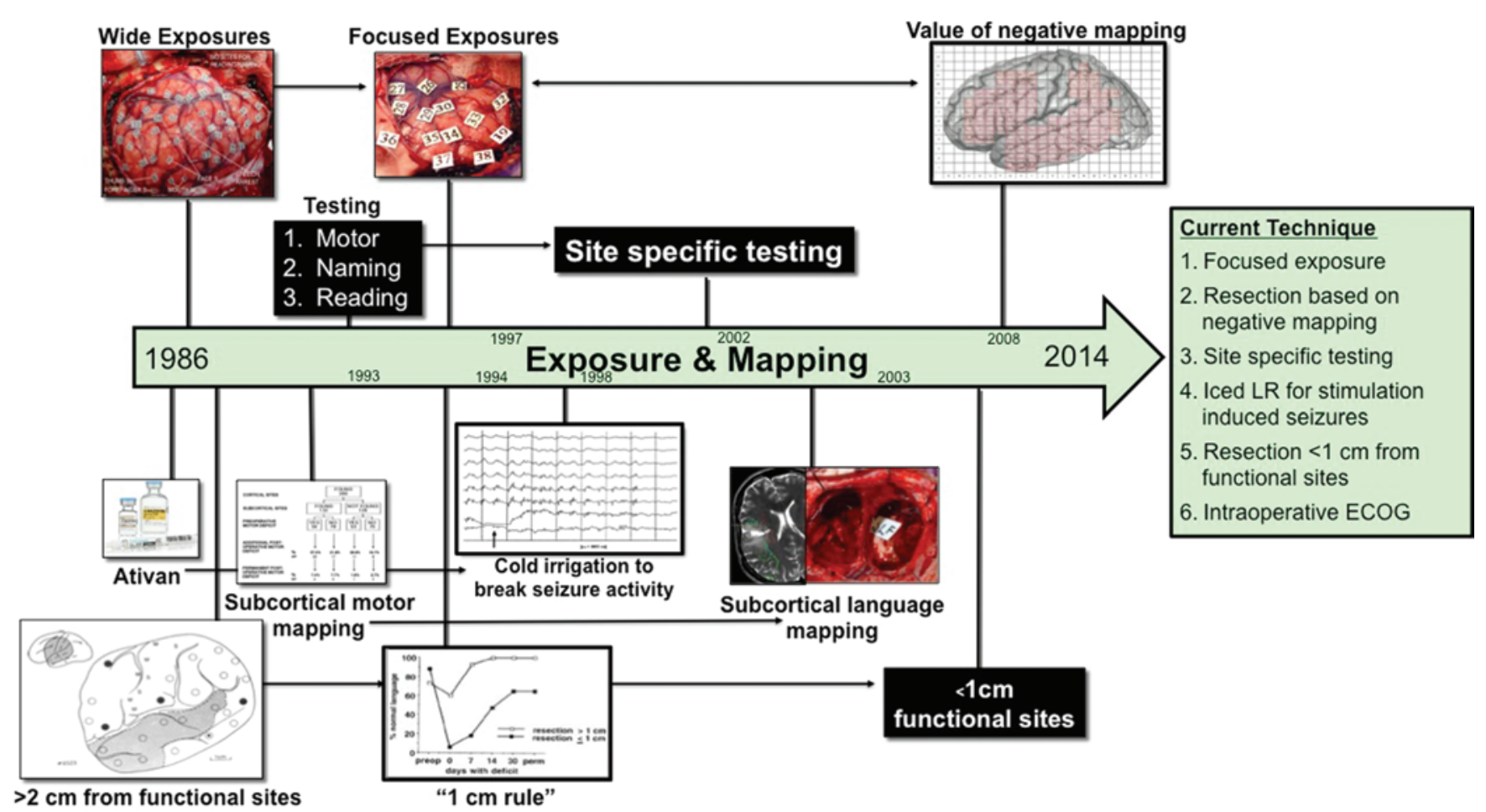

FIG. 4. Evolution of the surgical and mapping technique over time. LR = lactate Ringer's. "> $2 \mathrm{~cm}$ from functional sites" image from Ojemann et al: J Neurosurg 71:316-326, 1989. Published with permission. "Subcortical motor mapping" image from Keles et al: J Neurosurg 100:369-375, 2004. Published with permission. "1 cm rule" image from Haglund MM et al: Cortical localization of temporal lobe language sites in patients with gliomas. Neurosurgery 34:567-576, 1994. Published with permission. "Cold irrigation to break seizure activity" image from Sartorius et al: J Neurosurg 88:349-351, 1998. Published with permission. "Value of negative imaging" image from New England Journal of Medicine, Sanai et al: Functional outcome after language mapping for glioma resection, vol 358, pp 18-27. Copyright @ 2008 Massachusetts Medical Society. Reprinted with permission from Massachusetts Medical Society. Figure is available in color online only.

intolerance before the skin incision (propofol plus remifentanil switch to dexmedetomidine; propofol plus remifentanil with addition of dexmedetomidine; or dexmedetomidine plus remifentanil). Further analysis of the sedation technique revealed no correlation between sedation technique and tumor grade, tumor site, stimulation-induced seizures, LMA use, patient BMI, or aborted procedure (Table 4). This suggests no benefit of one drug regimen over another and the need for the surgical team to be flexible to successfully complete the awake craniotomy and mapping.

\section{Use of the LMA}

To successfully complete mapping and maximize safety in select high-risk patients, the LMA was used in $1 \%$ of patients $(n=8)$. In all cases, mapping was completed and the clinical indication for its use in each case included tumors with significant mass effect (greater than $2 \mathrm{~cm}$ of midline shift) and the need for hyperventilation due to tumor vascularity and venous engorgement secondary to hypercapnia. Patient BMI ranged from 24.1 to 47.5 (median 26.7). Tumor locations included temporal (6 patients), insular (1 patient), and frontal (1 patient) lobes. Tumor histopathologies included glioblastoma (5 patients), anaplastic astrocytoma (1 patient), and oligodendroglioma (2 patients). Subsequent analysis revealed no correlation between tumor site, tumor pathology, Mallampati score, ASA classification, aborted procedure, or patient BMI with use of an LMA (Table 5). There was a modestly increased length of stay for those patients in whom an LMA was used (3 days when LMA not used vs 5 days when LMA was used; $\mathrm{p}=0.001$ ).

\section{Stimulation-Induced Seizures}

Preoperative seizure history was noted in $70 \%$ of awake craniotomy patients and $68 \%$ were on antiepileptic medications prior to surgery (Table 3). The majority of these patients were on a single drug regimen (59\%); however, $10 \%$ used 2 or more antiepileptic drugs preoperatively. Cortical and subcortical mapping stimulation intensity was determined by intraoperative ECoG and was carried out at between 2 and $6 \mathrm{~mA}$ in all patients. Stimulationinduced seizures occurred in $3 \%$ of patients regardless of the stimulation current and were rapidly terminated with ice-cold Ringer's lactate solution except in 2 patients (see below) ${ }^{91}$ The incidence of stimulation-induced seizures ranges between $2.2 \%$ and $21.5 \%$ in the literature. $123,38,39,44,45,66,75,83,90,94,99$ The use of preoperative antiepileptic medications, tumor grade, and BMI had no effect on the occurrence of intraoperative stimulation-induced seizures (Table 6). A preoperative history of seizures $(95 \%$ vs $69 \% ; \mathrm{p}=0.01$ ) and tumor location (frontal lesions; $\mathrm{p}=$ 0.0003 ) were associated with stimulation-induced seizures. 
TABLE 3. Demographics of patients undergoing awake craniotomy $(n=611)^{*}$

\begin{tabular}{|c|c|}
\hline Variable & Value \\
\hline \multicolumn{2}{|l|}{ Age, yrs } \\
\hline Median & 43 \\
\hline Range & $13-84$ \\
\hline \multicolumn{2}{|l|}{ Tumor site } \\
\hline Frontal & $168(27)$ \\
\hline Insular & $128(21)$ \\
\hline Parietal & $92(15)$ \\
\hline Temporal & $223(36)$ \\
\hline \multicolumn{2}{|l|}{ Mallampati score } \\
\hline 1 & $147(24)$ \\
\hline 2 & $387(63)$ \\
\hline 3 & $71(12)$ \\
\hline 4 & $6(1)$ \\
\hline \multicolumn{2}{|l|}{ ASA classification } \\
\hline 1 (healthy patient) & $50(8)$ \\
\hline 2 (mild disease) & $466(76)$ \\
\hline 3 (severe disease) & $94(15)$ \\
\hline 4 (life-threatening disease) & $1(0.1)$ \\
\hline Mannitol & $327(54)$ \\
\hline \multicolumn{2}{|l|}{ Tumor side } \\
\hline Left & $572(94)$ \\
\hline Right & $39(6)$ \\
\hline Motor mapping & $342(56)$ \\
\hline Language mapping & $598(98)$ \\
\hline \multicolumn{2}{|l|}{ Tumor pathology } \\
\hline High grade & $335(55)$ \\
\hline Low grade & $259(42)$ \\
\hline Metastasis & $3(1)$ \\
\hline Other† & $14(2)$ \\
\hline Preop seizure history & $427(70)$ \\
\hline Preop anticonvulsant medications & $418(68)$ \\
\hline \multicolumn{2}{|l|}{ No. of anticonvulsant medications } \\
\hline 0 & $193(32)$ \\
\hline 1 & $358(59)$ \\
\hline 2 & $55(9)$ \\
\hline 3 & $5(0.8)$ \\
\hline Stimulation-induced seizures & $20(3)$ \\
\hline LMA & $8(1)$ \\
\hline Depression history & $75(12)$ \\
\hline Smokers & $75(12)$ \\
\hline Chronic cough & $30(5)$ \\
\hline \multicolumn{2}{|l|}{ BMI } \\
\hline Median & 25 \\
\hline Range & $16.6-56$ \\
\hline Low $(<24.9)$ & $255(42)$ \\
\hline High (>25) & $356(58)$ \\
\hline
\end{tabular}

(continued)
TABLE 3. Demographics of patients undergoing awake craniotomy $(n=611)^{*}$ (continued)

\begin{tabular}{cc}
\hline Variable & Value \\
\hline KPS score & \\
\hline$<80$ & $243(40)$ \\
\hline $90-100$ & $368(60)$ \\
\hline Aborted procedure & $3(0.5)$ \\
\hline Length of stay, days & 3 \\
\hline Median & $2-20$ \\
\hline Range & \\
\hline
\end{tabular}

* Values are presented as the number of patients (\%) unless noted otherwise. $\dagger$ Other includes cortical dysplasia, encephalitis, necrosis, abscess, hemangioma.

All 3 aborted cases had intraoperative stimulation-induced seizures. In the last few years, a technique is used to stimulate under a stream of cold irrigation fluid when either a seizure occurs or if the functional area is infiltrated with tumor. This does not prevent testing of the desired function, yet it often prevents a seizure from occurring.

\section{Awake Craniotomy Failure Rate}

An awake craniotomy failure (aborted mapping) was defined as the inability to complete cortical stimulation mapping and the tumor resection. Mapping was aborted in 3 cases $(0.5 \%)$ due to repetitive intraoperative seizures ( 2 cases) and emotional intolerance of the patient after a single stimulation-induced seizure (1 case). In the 2 operations aborted due to intraoperative seizures, 1 patient's stimulation-induced seizures were poorly controlled with iced Ringer's solution; therefore, the craniotomy was closed without resection. This patient was loaded on additional antiepileptic medications and returned to the operating room 3 days later for successful mapping and tumor resection. The other patient was able to complete half of the standard mapping protocol (1.5 rounds of testing); however, due to repeated stimulation-induced seizures that were poorly controlled with iced Ringer's solution, further intraoperative mapping was aborted and the resection was performed using the available mapping data combined with preoperative diffusion tensor imaging and neuronavigation. Another patient's surgery was aborted due to emotional intolerance and unwillingness to proceed with further surgery after a single stimulation-induced seizure (which was controlled with iced Ringer's solution). Thus, in all 3 patients, intraoperative stimulation-induced seizures were encountered. This is in comparison with the awake craniotomy failure rate reported in the literature which ranges between $2.3 \%$ and $6.4 \%$, whereas our failure rate was only $0.5 \% .^{66,75}$

Smoking status has long been considered to be associated with worse perioperative outcomes in neurosurgery patients. ${ }^{57}$ Twelve percent of patients were active smokers at the time of surgery. Smokers were more commonly found to have a depression history (20 smokers [27\%] and 55 nonsmokers [10\%]; $p=0.001$ ), as were those with chronic cough (6 smokers [8\%] and 14 nonsmokers [3\%]; $\mathrm{p}=0.01)$. However, there was no difference in any adverse 
TABLE 4. Sedation technique analysis $(n=611)$

\begin{tabular}{|c|c|c|c|c|}
\hline \multirow[b]{2}{*}{ Variable } & \multicolumn{3}{|c|}{ No. of Patients (\%) } & \multirow[b]{2}{*}{ p Value } \\
\hline & $\begin{array}{l}\text { Adjusted Technique } \\
\qquad(\mathrm{n}=258)\end{array}$ & $\begin{array}{l}\text { Dexmedetomidine + } \\
\text { Remifentanil }(n=26)\end{array}$ & $\begin{array}{l}\text { Propofol + Remifentanil } \\
\qquad(\mathrm{n}=327)\end{array}$ & \\
\hline Stimulation-induced seizures & $9(3)$ & $1(4)$ & $10(3)$ & 0.95 \\
\hline Tumor site & & & & 0.65 \\
\hline Frontal & $74(29)$ & $7(27)$ & $87(27)$ & \\
\hline Insular & $57(22)$ & $7(27)$ & $64(20)$ & \\
\hline Parietal & $33(13)$ & $2(8)$ & $57(17)$ & \\
\hline Temporal & $94(36)$ & $10(38)$ & $119(36)$ & \\
\hline Tumor pathology & & & & 0.82 \\
\hline High grade & $139(54)$ & $14(54)$ & $182(56)$ & \\
\hline Low grade & $114(44)$ & $12(46)$ & $133(41)$ & \\
\hline Metastasis & $1(0.4)$ & $3(12)$ & $2(1)$ & \\
\hline Other & $4(2)$ & $0(0)$ & $10(3)$ & \\
\hline Aborted procedure & $0(0)$ & $0(0)$ & $3(1)$ & 0.27 \\
\hline LMA & $2(1)$ & $1(4)$ & $5(2)$ & 0.37 \\
\hline BMI & & & & 0.08 \\
\hline Low $(<24.9)$ & $96(37)$ & $9(35)$ & $150(46)$ & \\
\hline High (>25) & $162(63)$ & $17(65)$ & $177(54)$ & \\
\hline
\end{tabular}

TABLE 5. Laryngeal mask airway use in awake craniotomy

\begin{tabular}{|c|c|c|c|}
\hline \multirow[b]{2}{*}{ Variable } & \multicolumn{2}{|c|}{ No. of Patients (\%) } & \multirow[b]{2}{*}{ p Value } \\
\hline & $\begin{array}{l}\text { No LMA } \\
(\mathrm{n}=603)\end{array}$ & $\begin{array}{l}\text { LMA Used } \\
\qquad(\mathrm{n}=8)\end{array}$ & \\
\hline Tumor site & & & 0.14 \\
\hline Frontal & $167(28)$ & $1(13)$ & \\
\hline Insular & $127(21)$ & $1(13)$ & \\
\hline Parietal & $92(15)$ & $0(0)$ & \\
\hline Temporal & $217(36)$ & $6(75)$ & \\
\hline Tumor pathology & & & 0.7 \\
\hline High grade & $329(55)$ & $6(75)$ & \\
\hline Low grade & $257(43)$ & $2(25)$ & \\
\hline Metastasis & $3(0.5)$ & $0(0)$ & \\
\hline Other & $14(2)$ & $0(0)$ & \\
\hline Mallampati score & & & 0.42 \\
\hline 1 & $144(24)$ & $3(38)$ & \\
\hline 2 & $384(64)$ & $3(38)$ & \\
\hline 3 & $69(11)$ & $2(25)$ & \\
\hline 4 & $6(1)$ & $0(0)$ & \\
\hline ASA classification & & & 0.76 \\
\hline 1 (healthy patient) & $50(8)$ & $0(0)$ & \\
\hline 2 (mild disease) & $460(76)$ & $6(75)$ & \\
\hline 3 (severe disease) & $92(15)$ & $2(25)$ & \\
\hline 4 (life-threatening disease) & $1(0.2)$ & $0(0)$ & \\
\hline Aborted procedure & $3(0.5)$ & $0(0)$ & 0.84 \\
\hline BMl & & & 0.15 \\
\hline $\operatorname{Low}(<24.9)$ & $254(42)$ & $1(13)$ & \\
\hline High (>25) & $349(58)$ & $7(88)$ & \\
\hline Average length of stay, days & 3 & 5 & 0.001 \\
\hline
\end{tabular}

perioperative outcome including stimulation-induced seizures (2 smokers [3\%] and 18 nonsmokers [3\%]; $\mathrm{p}=0.75)$, aborted mapping (0 smokers [0\%] and 3 nonsmokers [1\%]; $\mathrm{p}=0.99$ ), or LMA use (3 smokers [4\%] and 5 nonsmokers $[1 \%] ; p=0.06)$ between smokers and nonsmokers undergoing awake craniotomy. Smokers had a modestly increased but clinically insignificant length of stay (4 days for smokers and 3 days for nonsmokers; $p=0.001$ ).

\section{Perioperative Complications}

The perioperative complications included hemorrhage $(0.5 \%)$, stroke $(0.7 \%)$, infection $(1 \%)$, deep vein thrombosis or pulmonary embolism $(0.5 \%)$, early neurological deficit (status at time of discharge; $9 \%$ ), and late neurological deficit (3-month postoperative status; 3\%) (Table 7). The overall complication rate was $10 \%$, and the 30 -day readmission rate was $1 \%$. Postoperative complications in awake glioma surgery had no association with tumor location, pathology, LMA use, Mallampati score, ASA classification, sedation technique, or smoking status (Table 8). Smoking status and BMI have long been considered to be associated with worse perioperative outcomes in neurosurgery patients; however, our data suggest that smoking status is not a negative risk factor for patients undergoing awake brain tumor surgery. Postoperative complications were more prevalent in those with aborted mapping (3\% in patients with postoperative complications vs $0.2 \%$ in those without complications; $\mathrm{p}=$ $0.03)$ and stimulation-induced seizures (10\% with complications vs $3 \%$ in those without complications; $\mathrm{p}=0.003$ ) (Table 8).

\section{Discussion}

Using the largest single-surgeon experience ever reported to date, we describe the current indications, con- 
TABLE 6. Stimulation-induced seizures during awake craniotomy

\begin{tabular}{|c|c|c|c|}
\hline \multirow[b]{2}{*}{ Variable } & \multicolumn{2}{|c|}{ No. of Patients (\%) } & \multirow[b]{2}{*}{ p Value } \\
\hline & Stimulation-Induced Seizures $(n=20)^{*}$ & No Stimulation-Induced Seizures $(n=591)$ & \\
\hline Preop history of seizures & $19(95)$ & $408(69)$ & 0.01 \\
\hline Preop anticonvulsant use & $17(85)$ & $401(68)$ & 0.14 \\
\hline Tumor site & & & 0.0003 \\
\hline Frontal & $14(70)$ & $154(26)$ & \\
\hline Insular & $1(5)$ & $127(21)$ & \\
\hline Parietal & $2(10)$ & $90(15)$ & \\
\hline Temporal & $3(15)$ & $220(37)$ & \\
\hline Tumor pathology & & & 0.89 \\
\hline High grade & $11(55)$ & $324(55)$ & \\
\hline Low grade & $9(45)$ & $250(42)$ & \\
\hline Metastasis & $0(0)$ & $3(0.5)$ & \\
\hline Other & $0(0)$ & $14(2)$ & \\
\hline $\mathrm{BMI}$ & & & 0.12 \\
\hline Low $(<24.9)$ & $5(25)$ & $250(42)$ & \\
\hline High (>25) & $15(75)$ & $341(58)$ & \\
\hline
\end{tabular}

traindications, and evolving techniques for successful completion of awake language and sensorimotor mapping craniotomies to maximize perioperative safety and improve extent of resection for glioma patients. Our findings suggest that awake brain tumor surgery can be safely performed with few complications and a low failure rate, regardless of ASA classification, tumor site, tumor pathology, Mallampati score, BMI, smoking status, psychiatric history, seizure history, or tumor mass effect. We apply a team approach using trained operating room personnel employing specialized neuroanesthesia, which allows for better communication and prompt response to perioperative events if and when they occur. The anesthetic technique has evolved, offering improved patient comfort and limiting the influence $\mathrm{CO}_{2}$ retention and tumor mass effect through the use of a nasal trumpet, LMA, and acceptance of the importance of flexibility with regard to the initial sedation regimen on the part of both the neurosurgeon and the anesthesiologist. While some institutions rely heavily on the LMA for an awake craniotomy, we used it sparingly in $1 \%$ of cases with a very low failure rate. ${ }^{49,108}$ The identification and management of stimulation-induced seizures is critical for the successful completion of an awake craniotomy. Using intraoperative ECoG to minimize the stimulation current based on identifying after-discharge potentials, we found a low rate of stimulation-induced seizures (3\%), which were almost always controlled with iced Ringer's solution applied directly to the cortex.

Despite published series with failure rates of $2.3 \%-$ $6.4 \%$ and complication rates of $14 \%-32 \%$, these data illustrate a technique that offers a high degree of success and a low degree of morbidity. ${ }^{10,66,76,94,107}$ The failure rate using this technique is very low, occurring in $0.5 \%$ of awake craniotomies. The most common cause of failure was stimulation-induced seizures, which illustrates the importance of both preoperative and intraoperative seizure management for improved patient safety along with using lower stimula- tion current and iced Ringer's solution during stimulation when indicated as described above.

The limitations of this study are those inherent to a retrospective analysis. To overcome these limitations, we reviewed a large series of patients and included only those patients who had complete records available. Overall, the methodology as described in this study has evolved over time to be a safe, practical, reproducible, versatile, and reliable surgical procedure with few contraindications and a low failure rate. As such, it should be used as the neurosurgical standard of care for the removal of gliomas within or close to presumed functional areas.

\section{Conclusions}

Awake craniotomy for glioma patients can be safely performed with extremely low complication and failure rates regardless of ASA classification, Mallampati score, patient BMI, performance status, smoking status, psychi-

TABLE 7. Complications in awake craniotomy*

\begin{tabular}{lc}
\hline \multicolumn{1}{c}{ Variable } & Value \\
\hline Overall periop complication rate† & $63(10)$ \\
\hline Infection & $6(1)$ \\
\hline Postop hemorrhage & $3(0.5)$ \\
\hline Postop DVT or PE & $3(0.5)$ \\
\hline Postop stroke & $4(0.7)$ \\
\hline Early neurological deficit (at discharge) & $58(9)$ \\
\hline Late/residual neurological deficit (at 3 mos postop) & $16(3)$ \\
\hline 30-day readmission & $9(1)$ \\
\hline
\end{tabular}

* Some patients experienced more than 1 complication. Values are expressed as the number of patients (\%) unless noted otherwise.

$\dagger$ All complications captured in the study, including postoperative hemorrhage, infection, stroke, deep vein thrombosis/pulmonary embolism, new neurological deficit. 
TABLE 8. Complication analysis for awake craniotomy patients $(n=611)$

\begin{tabular}{|c|c|c|c|}
\hline \multirow[b]{2}{*}{ Variable } & \multicolumn{2}{|c|}{ No. of Patients (\%) } & \multirow[b]{2}{*}{ p Value } \\
\hline & Complications $(n=63)$ & No Complications $(n=548)$ & \\
\hline Tumor pathology & & & 0.57 \\
\hline High grade & $36(57)$ & $299(55)$ & \\
\hline Low grade & $27(43)$ & $232(42)$ & \\
\hline Metastasis & $0(0)$ & $3(0.5)$ & \\
\hline Other & $0(0)$ & $14(3)$ & \\
\hline Sedation technique & & & 0.61 \\
\hline Adjusted technique & $30(48)$ & $228(42)$ & \\
\hline Dexmedetomidine + remifentanil & $3(5)$ & $23(4)$ & \\
\hline Propofol + remifentanil & $30(48)$ & $297(54)$ & \\
\hline Mallampati score & & & 0.62 \\
\hline 1 & $17(27)$ & $130(24)$ & \\
\hline 2 & $41(65)$ & $346(63)$ & \\
\hline 3 & $5(8)$ & $66(12)$ & \\
\hline 4 & $0(0)$ & $6(1)$ & \\
\hline ASA classification & & & 0.21 \\
\hline 1 (healthy patient) & $1(2)$ & $49(9)$ & \\
\hline 2 (mild disease) & $53(84)$ & $413(75)$ & \\
\hline 3 (severe disease) & $9(14)$ & $85(16)$ & \\
\hline 4 (life-threatening disease) & $0(0)$ & $1(0.2)$ & \\
\hline Tumor site & & & 0.77 \\
\hline Frontal & $17(27)$ & $151(28)$ & \\
\hline Insular & $16(25)$ & $112(20)$ & \\
\hline Parietal & $10(16)$ & $82(15)$ & \\
\hline Temporal & $20(32)$ & $203(37)$ & \\
\hline Smoker & $11(17)$ & $64(12)$ & 0.2 \\
\hline LMA & $2(3)$ & $6(1)$ & 0.2 \\
\hline Stimulation-induced seizure & $6(10)$ & $14(3)$ & 0.003 \\
\hline Aborted mapping & $2(3)$ & $1(0.2)$ & 0.03 \\
\hline
\end{tabular}

atric and seizure history, tumor site, and tumor pathology. Surgeon flexibility with regard to the initial sedation regimen and adequate management of stimulation-induced intraoperative seizures are critical for successful completion of an awake craniotomy during glioma surgery.

\section{References}

1. Archer DP, McKenna JM, Morin L, Ravussin P: Conscioussedation analgesia during craniotomy for intractable epilepsy: a review of 354 consecutive cases. Can J Anaesth 35:338-344, 1988

2. Balki M, Manninen PH, McGuire GP, El-Beheiry H, Bernstein M: Venous air embolism during awake craniotomy in a supine patient. Can J Anaesth 50:835-838, 2003

3. Barker FG II, Prados MD, Chang SM, Gutin PH, Lamborn KR, Larson DA, et al: Radiation response and survival time in patients with glioblastoma multiforme. J Neurosurg 84:442-448, 1996

4. Bekker AY, Kaufman B, Samir H, Doyle W: The use of dexmedetomidine infusion for awake craniotomy. Anesth Analg 92:1251-1253, 2001

5. Berger MS: Lesions in functional ("eloquent") cortex and subcortical white matter. Clin Neurosurg 41:444-463, 1994
6. Berger MS, Ojemann GA: Intraoperative brain mapping techniques in neuro-oncology. Stereotact Funct Neurosurg 58:153-161, 1992

7. Berkenstadt H, Perel A, Hadani M, Unofrievich I, Ram Z: Monitored anesthesia care using remifentanil and propofol for awake craniotomy. J Neurosurg Anesthesiol 13:246249, 2001

8. Berman JI, Berger MS, Chung SW, Nagarajan SS, Henry RG: Accuracy of diffusion tensor magnetic resonance imaging tractography assessed using intraoperative subcortical stimulation mapping and magnetic source imaging. J Neurosurg 107:488-494, 2007

9. Bilotta F, Rosa G: 'Anesthesia' for awake neurosurgery. Curr Opin Anaesthesiol 22:560-565, 2009

10. Blanshard HJ, Chung F, Manninen PH, Taylor MD, Bernstein M: Awake craniotomy for removal of intracranial tumor: considerations for early discharge. Anesth Analg 92:89-94, 2001

11. Bloch O, Han SJ, Cha S, Sun MZ, Aghi MK, McDermott MW, et al: Impact of extent of resection for recurrent glioblastoma on overall survival. Clinical article. J Neurosurg 117:1032-1038, 2012

12. Bogomolny DL, Petrovich NM, Hou BL, Peck KK, Kim MJ, Holodny AI: Functional MRI in the brain tumor patient. Top Magn Reson Imaging 15:325-335, 2004 
13. Bonhomme V, Franssen C, Hans P: Awake craniotomy. Eur J Anaesthesiol 26:906-912, 2009

14. Buckner JC, Schomberg PJ, McGinnis WL, Cascino TL, Scheithauer BW, O'Fallon JR, et al: A phase III study of radiation therapy plus carmustine with or without recombinant interferon-alpha in the treatment of patients with newly diagnosed high-grade glioma. Cancer 92:420-433, 2001

15. Burchiel KJ, Clarke H, Ojemann GA, Dacey RG, Winn HR: Use of stimulation mapping and corticography in the excision of arteriovenous malformations in sensorimotor and language-related neocortex. Neurosurgery 24:322-327, 1989

16. Carrabba G, Venkatraghavan L, Bernstein M: Day surgery awake craniotomy for removing brain tumours: technical note describing a simple protocol. Minim Invasive Neurosurg 51:208-210, 2008

17. Chang EF, Clark A, Smith JS, Polley MY, Chang SM, Barbaro NM, et al: Functional mapping-guided resection of low-grade gliomas in eloquent areas of the brain: improvement of long-term survival. Clinical article. J Neurosurg 114:566-573, 2011

18. Chang EF, Potts MB, Keles GE, Lamborn KR, Chang SM, Barbaro NM, et al: Seizure characteristics and control following resection in 332 patients with low-grade gliomas. J Neurosurg 108:227-235, 2008

19. Chang EF, Smith JS, Chang SM, Lamborn KR, Prados MD, Butowski N, et al: Preoperative prognostic classification system for hemispheric low-grade gliomas in adults. J Neurosurg 109:817-824, 2008

20. Chang SM, Parney IF, Huang W, Anderson FA Jr, Asher AL, Bernstein M, et al: Patterns of care for adults with newly diagnosed malignant glioma. JAMA 293:557-564, 2005

21. Claus EB, Horlacher A, Hsu L, Schwartz RB, Dello-Iacono $\mathrm{D}$, Talos F, et al: Survival rates in patients with low-grade glioma after intraoperative magnetic resonance image guidance. Cancer 103:1227-1233, 2005

22. Conte V, Baratta P, Tomaselli P, Songa V, Magni L, Stocchetti N: Awake neurosurgery: an update. Minerva Anestesiol 74:289-292, 2008

23. Conte V, Magni L, Songa V, Tomaselli P, Ghisoni L, Magnoni S, et al: Analysis of propofol/remifentanil infusion protocol for tumor surgery with intraoperative brain mapping. J Neurosurg Anesthesiol 22:119-127, 2010

24. Costello TG, Cormack JR: Anaesthesia for awake craniotomy: a modern approach. J Clin Neurosci 11:16-19, 2004

25. Costello TG, Cormack JR, Mather LE, LaFerlita B, Murphy MA, Harris K: Plasma levobupivacaine concentrations following scalp block in patients undergoing awake craniotomy. Br J Anaesth 94:848-851, 2005

26. Curran WJ Jr, Scott CB, Horton J, Nelson JS, Weinstein AS, Nelson DF, et al: Does extent of surgery influence outcome for astrocytoma with atypical or anaplastic foci (AAF)? A report from three Radiation Therapy Oncology Group (RTOG) trials. J Neurooncol 12:219-227, 1992

27. Danks RA, Rogers M, Aglio LS, Gugino LD, Black PM: Patient tolerance of craniotomy performed with the patient under local anesthesia and monitored conscious sedation. Neurosurgery 42:28-36, 1998

28. De Benedictis A, Moritz-Gasser S, Duffau H: Awake mapping optimizes the extent of resection for low-grade gliomas in eloquent areas. Neurosurgery 66:1074-1084, 2010

29. De Witt Hamer PC, Robles SG, Zwinderman AH, Duffau H, Berger MS: Impact of intraoperative stimulation brain mapping on glioma surgery outcome: a meta-analysis. J Clin Oncol 30:2559-2565, 2012

30. Dinapoli RP, Brown LD, Arusell RM, Earle JD, O'Fallon JR, Buckner JC, et al: Phase III comparative evaluation of PCNU and carmustine combined with radiation therapy for highgrade glioma. J Clin Oncol 11:1316-1321, 1993

31. Duffau H: Brain plasticity: from pathophysiological mecha- nisms to therapeutic applications. J Clin Neurosci 13:885897,2006

32. Duffau H: The huge plastic potential of adult brain and the role of connectomics: New insights provided by serial mappings in glioma surgery. Cortex 58:325-337, 2013

33. Duffau H: Lessons from brain mapping in surgery for lowgrade glioma: insights into associations between tumour and brain plasticity. Lancet Neurol 4:476-486, 2005

34. Duffau H, Capelle L, Denvil D, Sichez N, Gatignol P, Taillandier L, et al: Usefulness of intraoperative electrical subcortical mapping during surgery for low-grade gliomas located within eloquent brain regions: functional results in a consecutive series of 103 patients. J Neurosurg 98:764-778, 2003

35. Englot DJ, Berger MS, Barbaro NM, Chang EF: Predictors of seizure freedom after resection of supratentorial low-grade gliomas. A review. J Neurosurg 115:240-244, 2011

36. Englot DJ, Han SJ, Berger MS, Barbaro NM, Chang EF: Extent of surgical resection predicts seizure freedom in lowgrade temporal lobe brain tumors. Neurosurgery 70:921928,2012

37. Fernández Coello A, Moritz-Gasser S, Martino J, Martinoni M, Matsuda R, Duffau H: Selection of intraoperative tasks for awake mapping based on relationships between tumor location and functional networks. J Neurosurg 119:13801394,2013

38. Gignac E, Manninen PH, Gelb AW: Comparison of fentanyl, sufentanil and alfentanil during awake craniotomy for epilepsy. Can J Anaesth 40:421-424, 1993

39. Grossman R, Nossek E, Sitt R, Hayat D, Shahar T, Barzilai O, et al: Outcome of elderly patients undergoing awake-craniotomy for tumor resection. Ann Surg Oncol 20:1722-1728, 2013

40. Guggisberg AG, Honma SM, Findlay AM, Dalal SS, Kirsch $\mathrm{HE}$, Berger MS, et al: Mapping functional connectivity in patients with brain lesions. Ann Neurol 63:193-203, 2008

41. Gupta DK, Chandra PS, Ojha BK, Sharma BS, Mahapatra AK, Mehta VS: Awake craniotomy versus surgery under general anesthesia for resection of intrinsic lesions of eloquent cortex - a prospective randomised study. Clin Neurol Neurosurg 109:335-343, 2007

42. Haglund MM, Berger MS, Shamseldin M, Lettich E, Ojemann GA: Cortical localization of temporal lobe language sites in patients with gliomas. Neurosurgery 34:567-576, 1994

43. Han SJ, Yang I, Ahn BJ, Otero JJ, Tihan T, McDermott MW, et al: Clinical characteristics and outcomes for a modern series of primary gliosarcoma patients. Cancer 116:1358-1366, 2010

44. Herrick IA, Craen RA, Gelb AW, McLachlan RS, Girvin JP, Parrent AG, et al: Propofol sedation during awake craniotomy for seizures: electrocorticographic and epileptogenic effects. Anesth Analg 84:1280-1284, 1997

45. Herrick IA, Craen RA, Gelb AW, Miller LA, Kubu CS, Girvin JP, et al: Propofol sedation during awake craniotomy for seizures: patient-controlled administration versus neurolept analgesia. Anesth Analg 84:1285-1291, 1997

46. Hirsch J, Ruge MI, Kim KH, Correa DD, Victor JD, Relkin NR, et al: An integrated functional magnetic resonance imaging procedure for preoperative mapping of cortical areas associated with tactile, motor, language, and visual functions. Neurosurgery 47:711-722, 2000

47. Horsley V: Remarks on ten consecutive cases of operations upon the brain and cranial cavity to illustrate the details and safety of the method employed. BMJ 1:863-865, 1887

48. Jeremic B, Grujicic D, Antunovic V, Djuric L, Stojanovic $\mathrm{M}$, Shibamoto Y: Influence of extent of surgery and tumor location on treatment outcome of patients with glioblastoma multiforme treated with combined modality approach. J Neurooncol 21:177-185, 1994 
49. Keifer JC, Dentchev D, Little K, Warner DS, Friedman AH, Borel CO: A retrospective analysis of a remifentanil/propofol general anesthetic for craniotomy before awake functional brain mapping. Anesth Analg 101:502-508, 2005

50. Keles GE, Anderson B, Berger MS: The effect of extent of resection on time to tumor progression and survival in patients with glioblastoma multiforme of the cerebral hemisphere. Surg Neurol 52:371-379, 1999

51. Keles GE, Chang EF, Lamborn KR, Tihan T, Chang CJ, Chang SM, et al: Volumetric extent of resection and residual contrast enhancement on initial surgery as predictors of outcome in adult patients with hemispheric anaplastic astrocytoma. J Neurosurg 105:34-40, 2006

52. Keles GE, Lamborn KR, Chang SM, Prados MD, Berger MS: Volume of residual disease as a predictor of outcome in adult patients with recurrent supratentorial glioblastomas multiforme who are undergoing chemotherapy. J Neurosurg 100:41-46, 2004

53. Keles GE, Lundin DA, Lamborn KR, Chang EF, Ojemann G, Berger MS: Intraoperative subcortical stimulation mapping for hemispherical perirolandic gliomas located within or adjacent to the descending motor pathways: evaluation of morbidity and assessment of functional outcome in 294 patients. J Neurosurg 100:369-375, 2004

54. Kim SS, McCutcheon IE, Suki D, Weinberg JS, Sawaya R, Lang FF, et al: Awake craniotomy for brain tumors near eloquent cortex: correlation of intraoperative cortical mapping with neurological outcomes in 309 consecutive patients. Neurosurgery 64:836-845, 345-346, 2009

55. Lacroix M, Abi-Said D, Fourney DR, Gokaslan ZL, Shi W, DeMonte F, et al: A multivariate analysis of 416 patients with glioblastoma multiforme: prognosis, extent of resection, and survival. J Neurosurg 95:190-198, 2001

56. Lamborn KR, Chang SM, Prados MD: Prognostic factors for survival of patients with glioblastoma: recursive partitioning analysis. Neuro-oncol 6:227-235, 2004

57. Lau D, Berger MS, Khullar D, Maa J: The impact of smoking on neurosurgical outcomes. J Neurosurg 119:1323-1330, 2013

58. Leighton C, Fisher B, Bauman G, Depiero S, Stitt L, MacDonald D, et al: Supratentorial low-grade glioma in adults: an analysis of prognostic factors and timing of radiation. J Clin Oncol 15:1294-1301, 1997

59. LeRoux PD, Berger MS, Haglund MM, Pilcher WH, Ojemann GA: Resection of intrinsic tumors from nondominant face motor cortex using stimulation mapping: report of two cases. Surg Neurol 36:44-48, 1991

60. Manninen PH, Tan TK: Postoperative nausea and vomiting after craniotomy for tumor surgery: a comparison between awake craniotomy and general anesthesia. J Clin Anesth 14:279-283, 2002

61. McGirt MJ, Chaichana KL, Gathinji M, Attenello FJ, Than $\mathrm{K}$, Olivi A, et al: Independent association of extent of resection with survival in patients with malignant brain astrocytoma. J Neurosurg 110:156-162, 2009

62. Meyer PT, Sturz L, Schreckenberger M, Spetzger U, Meyer GF, Setani KS, et al: Preoperative mapping of cortical language areas in adult brain tumour patients using PET and individual non-normalised SPM analyses. Eur J Nucl Med Mol Imaging 30:951-960, 2003

63. Mueller WM, Yetkin FZ, Hammeke TA, Morris GL III, Swanson SJ, Reichert K, et al: Functional magnetic resonance imaging mapping of the motor cortex in patients with cerebral tumors. Neurosurgery 39:515-521, 1996

64. Nakamura M, Konishi N, Tsunoda S, Nakase H, Tsuzuki T, Aoki $\mathrm{H}$, et al: Analysis of prognostic and survival factors related to treatment of low-grade astrocytomas in adults. Oncology 58:108-116, 2000

65. Nitta T, Sato K: Prognostic implications of the extent of sur- gical resection in patients with intracranial malignant gliomas. Cancer 75:2727-2731, 1995

66. Nossek E, Matot I, Shahar T, Barzilai O, Rapoport Y, Gonen $\mathrm{T}$, et al: Failed awake craniotomy: a retrospective analysis in 424 patients undergoing craniotomy for brain tumor. J Neurosurg 118:243-249, 2013

67. Nossek E, Matot I, Shahar T, Barzilai O, Rapoport Y, Gonen $\mathrm{T}$, et al: Intraoperative seizures during awake craniotomy: incidence and consequences: analysis of 477 patients. Neurosurgery 73:135-140, 2013

68. Ohue S, Kohno S, Inoue A, Yamashita D, Harada H, Kumon $Y$, et al: Accuracy of diffusion tensor magnetic resonance imaging-based tractography for surgery of gliomas near the pyramidal tract: a significant correlation between subcortical electrical stimulation and postoperative tractography. Neurosurgery 70:283-294, 2012

69. Ojemann G, Ojemann J, Lettich E, Berger M: Cortical language localization in left, dominant hemisphere. An electrical stimulation mapping investigation in 117 patients. J Neurosurg 71:316-326, 1989

70. Ojemann GA, Creutzfeldt O, Lettich E, Haglund MM: Neuronal activity in human lateral temporal cortex related to short-term verbal memory, naming and reading. Brain 111:1383-1403, 1988

71. Olsen KS: The asleep-awake technique using propofolremifentanil anaesthesia for awake craniotomy for cerebral tumours. Eur J Anaesthesiol 25:662-669, 2008

72. Oszvald A, Güresir E, Setzer M, Vatter H, Senft C, Seifert V, et al: Glioblastoma therapy in the elderly and the importance of the extent of resection regardless of age. J Neurosurg 116:357-364, 2012

73. Palese A, Skrap M, Fachin M, Visioli S, Zannini L: The experience of patients undergoing awake craniotomy: in the patients' own words. A qualitative study. Cancer Nurs 31:166-172, 2008

74. Penfield W, Boldrey E: Somatic motor and sensory representation in the cerebral cortex of man as studied by electrical stimulation. Brain 60:389-443, 1939

75. Pereira LC, Oliveira KM, L'Abbate GL, Sugai R, Ferreira JA, da Motta LA: Outcome of fully awake craniotomy for lesions near the eloquent cortex: analysis of a prospective surgical series of 79 supratentorial primary brain tumors with long follow-up. Acta Neurochir (Wien) 151:1215-1230, 2009

76. Peruzzi P, Bergese SD, Viloria A, Puente EG, Abdel-Rasoul M, Chiocca EA: A retrospective cohort-matched comparison of conscious sedation versus general anesthesia for supratentorial glioma resection. Clinical article. J Neurosurg 114:633-639, 2011

77. Philippon JH, Clemenceau SH, Fauchon FH, Foncin JF: Supratentorial low-grade astrocytomas in adults. Neurosurgery 32:554-559, 1993

78. Piccioni F, Fanzio M: Management of anesthesia in awake craniotomy. Minerva Anestesiol 74:393-408, 2008

79. Pope WB, Sayre J, Perlina A, Villablanca JP, Mischel PS, Cloughesy TF: MR imaging correlates of survival in patients with high-grade gliomas. AJNR Am J Neuroradiol 26:2466-2474, 2005

80. Potts MB, Smith JS, Molinaro AM, Berger MS: Natural history and surgical management of incidentally discovered low-grade gliomas. J Neurosurg 116:365-372, 2012

81. Quiñones-Hinojosa A, Ojemann SG, Sanai N, Dillon WP, Berger MS: Preoperative correlation of intraoperative cortical mapping with magnetic resonance imaging landmarks to predict localization of the Broca area. J Neurosurg 99:311-318, 2003

82. Rajan B, Pickuth D, Ashley S, Traish D, Monro P, Elyan S, et al: The management of histologically unverified presumed cerebral gliomas with radiotherapy. Int J Radiat Oncol Biol Phys 28:405-413, 1994 
83. Sacko O, Lauwers-Cances V, Brauge D, Sesay M, Brenner A, Roux FE: Awake craniotomy vs surgery under general anesthesia for resection of supratentorial lesions. Neurosurgery 68:1192-1199, 2011

84. Sanai N, Berger MS: Mapping the horizon: techniques to optimize tumor resection before and during surgery. Clin Neurosurg 55:14-19, 2008

85. Sanai N, Berger MS: Operative techniques for gliomas and the value of extent of resection. Neurotherapeutics 6:478486, 2009

86. Sanai N, Martino J, Berger MS: Morbidity profile following aggressive resection of parietal lobe gliomas. J Neurosurg 116:1182-1186, 2012

87. Sanai N, Mirzadeh Z, Berger MS: Functional outcome after language mapping for glioma resection. $\mathbf{N}$ Engl J Med 358:18-27, 2008

88. Sanai N, Polley MY, Berger MS: Insular glioma resection: assessment of patient morbidity, survival, and tumor progression. J Neurosurg 112:1-9, 2010

89. Sanai N, Polley MY, McDermott MW, Parsa AT, Berger MS: An extent of resection threshold for newly diagnosed glioblastomas. J Neurosurg 115:3-8, 2011

90. Sarang A, Dinsmore J: Anaesthesia for awake craniotomyevolution of a technique that facilitates awake neurological testing. Br J Anaesth 90:161-165, 2003

91. Sartorius CJ, Berger MS: Rapid termination of intraoperative stimulation-evoked seizures with application of cold Ringer's lactate to the cortex. Technical note. J Neurosurg 88:349-351, 1998

92. Sartorius CJ, Wright G: Intraoperative brain mapping in a community setting - technical considerations. Surg Neurol 47:380-388, 1997

93. Schreckenberger M, Spetzger U, Sabri O, Meyer PT, Zeggel $\mathrm{T}$, Zimny M, et al: Localisation of motor areas in brain tumour patients: a comparison of preoperative [18F]FDGPET and intraoperative cortical electrostimulation. Eur J Nucl Med 28:1394-1403, 2001

94. Serletis D, Bernstein M: Prospective study of awake craniotomy used routinely and nonselectively for supratentorial tumors. J Neurosurg 107:1-6, 2007

95. Shaw E, Arusell R, Scheithauer B, O'Fallon J, O’Neill B, Dinapoli R, et al: Prospective randomized trial of low- versus high-dose radiation therapy in adults with supratentorial low-grade glioma: initial report of a North Central Cancer Treatment Group/Radiation Therapy Oncology Group/ Eastern Cooperative Oncology Group study. J Clin Oncol 20:2267-2276, 2002

96. Shibamoto Y, Yamashita J, Takahashi M, Yamasaki T, Kikuchi H, Abe M: Supratentorial malignant glioma: an analysis of radiation therapy in 178 cases. Radiother Oncol 18:9-17, 1990

97. Simpson JR, Horton J, Scott C, Curran WJ, Rubin P, Fischbach J, et al: Influence of location and extent of surgical resection on survival of patients with glioblastoma multiforme: results of three consecutive Radiation Therapy Oncology Group (RTOG) clinical trials. Int J Radiat Oncol Biol Phys 26:239-244, 1993

98. Skirboll SS, Ojemann GA, Berger MS, Lettich E, Winn HR: Functional cortex and subcortical white matter located within gliomas. Neurosurgery 38:678-685, 1996

99. Skucas AP, Artru AA: Anesthetic complications of awake craniotomies for epilepsy surgery. Anesth Analg 102:882887,2006

100. Smith JS, Chang EF, Lamborn KR, Chang SM, Prados MD, Cha S, et al: Role of extent of resection in the long-term outcome of low-grade hemispheric gliomas. J Clin Oncol 26: $1338-1345,2008$

101. Southwell DG, Garcia PA, Berger MS, Barbaro NM, Chang
EF: Long-term seizure control outcomes after resection of gangliogliomas. Neurosurgery 70:1406-1414, 2012

102. Stark AM, Nabavi A, Mehdorn HM, Blömer U: Glioblastoma multiforme-report of 267 cases treated at a single institution. Surg Neurol 63:162-169, 2005

103. Stummer W, Reulen HJ, Meinel T, Pichlmeier U, Schumacher W, Tonn JC, et al: Extent of resection and survival in glioblastoma multiforme: identification of and adjustment for bias. Neurosurgery 62:564-576, 2008

104. Szelényi A, Bello L, Duffau H, Fava E, Feigl GC, Galanda $\mathrm{M}$, et al: Intraoperative electrical stimulation in awake craniotomy: methodological aspects of current practice. Neurosurg Focus 28(2):E7, 2010

105. Tarapore PE, Martino J, Guggisberg AG, Owen J, Honma SM, Findlay A, et al: Magnetoencephalographic imaging of resting-state functional connectivity predicts postsurgical neurological outcome in brain gliomas. Neurosurgery 71:1012-1022, 2012

106. Tate MC, Kim CY, Chang EF, Polley MY, Berger MS: Assessment of morbidity following resection of cingulate gyrus gliomas. Clinical article. J Neurosurg 114:640647,2011

107. Taylor MD, Bernstein M: Awake craniotomy with brain mapping as the routine surgical approach to treating patients with supratentorial intraaxial tumors: a prospective trial of 200 cases. J Neurosurg 90:35-41, 1999

108. Trinh VT, Fahim DK, Shah K, Tummala S, McCutcheon IE, Sawaya R, et al: Subcortical injury is an independent predictor of worsening neurological deficits following awake craniotomy procedures. Neurosurgery 72:160-169, 2013

109. Ushio Y, Kochi M, Hamada J, Kai Y, Nakamura H: Effect of surgical removal on survival and quality of life in patients with supratentorial glioblastoma. Neurol Med Chir (Tokyo) 45:454-461, 2005

110. van Veelen ML, Avezaat CJ, Kros JM, van Putten W, Vecht C: Supratentorial low grade astrocytoma: prognostic factors, dedifferentiation, and the issue of early versus late surgery. J Neurol Neurosurg Psychiatry 64:581-587, 1998

111. Vecht CJ, Avezaat CJ, van Putten WL, Eijkenboom WM, Stefanko SZ: The influence of the extent of surgery on the neurological function and survival in malignant glioma. A retrospective analysis in 243 patients. J Neurol Neurosurg Psychiatry 53:466-471, 1990

112. Vlieger EJ, Majoie CB, Leenstra S, Den Heeten GJ: Functional magnetic resonance imaging for neurosurgical planning in neurooncology. Eur Radiol 14:1143-1153, 2004

113. Yeh SA, Ho JT, Lui CC, Huang YJ, Hsiung CY, Huang EY: Treatment outcomes and prognostic factors in patients with supratentorial low-grade gliomas. Br J Radiol 78:230235,2005

\section{Author Contributions}

Conception and design: Meng, Berger. Acquisition of data: all authors. Analysis and interpretation of data: all authors. Drafting the article: Hervey-Jumper, Lau, Molinaro. Critically revising the article: all authors. Reviewed submitted version of manuscript: all authors. Approved the final version of the manuscript on behalf of all authors: Hervey-Jumper. Study supervision: Berger.

\section{Correspondence}

Shawn L. Hervey-Jumper, Department of Neurological Surgery, University of California San Francisco, 505 Parnassus Ave., M779, San Francisco, CA 94143. email: herveyju@umich.edu. 